\title{
Drivers of top performing farmers
}

\author{
M.K. ELLIOTT and R.D.N. WAKELIN \\ UMR Research, 46 Parnell Rd, Auckland, New Zealand \\ Beef + Lamb New Zealand, 154 Featherston Street, Wellington 6140, New Zealand \\ marc@umr.co.nz
}

\begin{abstract}
The core drivers for why top performing farmers operate the way they do is the importance of both family and the 'way of life' that farming provides. While profitability is critical, when it is boiled down, profits allow top performers to provide opportunities for their families, and live the farming 'way of life' that appeals so deeply to them. These two factors are then followed by a diverse range of drivers that all form the fabric of farming that drive top performers to get out of bed and push for even greater productivity and profits.
\end{abstract}

Keywords: Performance drivers, way of life, profitability, dynamic challenge, attention to detail, efficiency

\section{Key messages}

- New Zealand's high performing sheep and beef farmers are driven by much more than profitability and are usually underpinned by a strong farm team.

- They have a deep connection to the land and the "way of life' that sheep and beef farming can provide.

- The high performers have a strong focus on doing the basics well, they pay attention to detail, run efficient, and simple systems, while taking calculated risks to continually improve their performance.

\section{Introduction}

This paper presents the main findings from a study commissioned by the Red Meat Profit Partnership (RMPP) conducted during mid to late 2014 and fully reported in November 2014. The study is part of a larger research program to help develop initial strategies for improving performance in the New Zealand sheep and beef industry. The primary objective of this study was to identify the attitudinal drivers of high performing sheep and beef farmers.

The key challenge for this study was finding a credible sample of top and mid-performing farmers. The partnership of the RMPP meant that across the partners there was enough scope to achieve a sample based on objective financial results.

\section{Methodology}

This study aimed to gain an in-depth understanding of farmers' experiences and perceptions rather than providing counts or measures, and as such qualitative research was used. Unstructured qualitative interviewing allowed exploration of the attitudes and behaviours of top-performing farmers, and helped the understanding of what drove top-performers to operate at the levels they did, and the practices they adopted to succeed.

The primary focus of this study was to conduct research among 'top' performing famers. To more fully understand what makes these 'top' performers different we also needed to contrast them with a comparison group of 'mid-tier' farmers. This paper focuses on topperforming farmers; however, some comparisons are made with those in the mid-tier to help illustrate where key differences existed.

\section{Defining the sample}

The main measure used to define performance was economic farm surplus (EFS), supplemented with return on assets (ROA). For both of these measures farmers' average results over the last 3 years were taken into account. High performance over time was an important factor in identifying potential candidates. There were examples of higher performing farms, but not at a consistent 'year on year' level.

All of the mid-tier farmers were taken from the Beef and Lamb New Zealand (B+LNZ) Sheep and Beef farmer Economic Service survey database. To be eligible these farmers financial performance had to be in the second and third performance quartiles.

The final sample for this study consisted of 58 farmers ( $\mathrm{n}=30$ top-performers; $\mathrm{n}=28$ mid-tiers).

Table 1 Summary of the financial performance of the topperforming farmers who participated.

\begin{tabular}{lccc}
\hline & \multicolumn{3}{c}{ Financial Years } \\
& $\mathbf{1 2 / 1 3}$ & $\mathbf{1 1 / 1 2}$ & $\mathbf{1 0 / 1 1}$ \\
\hline EFS/ha & & & \\
Top 5 (Av.) & $\$ 704$ & $\$ 1,054$ & $\$ 893$ \\
Top 30 (Av.) & $\$ 435$ & $\$ 562$ & $\$ 380$ \\
\hline ROA & & & \\
Top 5 (Av.) & $8.6 \%$ & $13.2 \%$ & $10.9 \%$ \\
Top 30 (Av.) & $6.5 \%$ & $8.8 \%$ & $6.0 \%$ \\
\hline
\end{tabular}


The farmers who participated in this study were located across New Zealand and all the major classes of sheep and beef farming as defined by B+LNZ were included: North Island (NI) hill country, NI hard hill country, NI intensive finishing, South Island (SI) High country, SI high country running fine wool sheep, SI breeding/finishing, SI intensive finishing and SI mixed cropping/finishing.

\section{The interview}

The qualitative approach used in this study was a face-to-face semi-structured in-depth interview, each interview lasting approximately 60 minutes. The interviews used a flexible line of questioning that was designed to more deeply understand what drove the farmers to perform at the levels they did. All interviews were conducted at the farms of the participants and in many cases a farm team (husband and wife or father and son) was interviewed.

\section{Analysis and reporting notes}

The in-depth interviews were tape-recorded and the majority were transcribed, followed by thematic content analysis on the transcriptions and researchers' notes, and key themes were identified.

Throughout the paper there are comparisons made between top-performing and mid-tier farmers. As a general rule, the report presents themes that relate to the top-performing farmers followed by those associated with mid-tier ones. Verbatim farmer quotes are selectively used throughout this paper, taking the reader a step closer to the participants.

\section{Note on qualitative research}

This is a qualitative research study and has been designed to uncover an in-depth understanding of what drives top-performing farmers. Qualitative research allows conclusions about the range of views topperforming farmers have on a topic, however, it does not allow conclusions to be drawn on what percentages of these farmers hold the identified views.

\section{Results and Discussion}

Figure 1 summarises the main drivers of performance for top-performing farmers. The drivers for the mid-tier farmers are similar in some ways but different in others. The 'family and way of life' driver was also central to the mid-tier farmers included in this study. The mid-tier farmers will also be working to make a profit but they will not be achieving the same level of profitability and some may be more driven by capital growth.

With the mid-tier farmers (to varying degrees) it is likely that 'passion for performance', 'industry confidence' 'passion for industry and people' and the 'dynamic challenge' will be drivers for them as well.

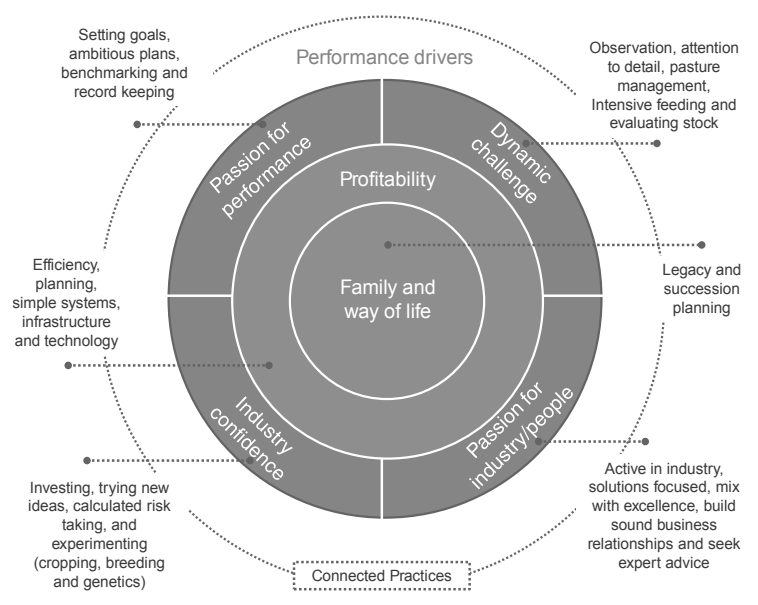

Figure 1 Summary of the main drivers of performance for top-performing farmers.

However, the relevance of these drivers for motivating them to go the extra mile will not be anywhere near as strong as it is for the top-performing farmers. The topperforming farmers have an in-built drive for success.

The link between these drivers and then successfully carrying out the connected practices will be less strong with the mid-tier farmers compared to their higher performing counterparts. This study suggests that most farmers have a sense of what needs to be done to farm successfully but only the top-performers are both motivated to and know how to consistently execute plans day after day. They know what needs to be done, and they can do it. If they don't know how to do something, they will find out, learn and execute.

\section{Family and way of life}

For almost all farmers the 'way of life' that farming provided was central to the attraction of sheep and beef farming. Family was an important driver of performance as many sought to be able to provide their children with similar opportunities as they were given by their parents. First generation top-performing farmers were also strongly driven by a desire to build legacy in their business. This meant succession planning was important to most farmers. The top-performers tended to be more confident that they would succeed in succession planning particularly because their operations were profitable. There was also the sense of carrying on a family legacy that seemed to drive performance, with many describing the family history of their farm with pride. There was a keen desire to build on and develop the potential in the farm that was first carved out by those who went before.

"I am third generation now and you spend your day out and around the place and you see what your grandfather achieved. This house we are in here my grandfather built this himself, took him 
$41 / 2$ years, started in 1957 and finished in 1961, and that was out of poverty" (Central Otago, topperformer, male)

The way of life that sheep and beef farming provided was a key driver for keeping farmers on the land. For top-performers, farming allowed them to spend time with family while making good profits and maintaining an enviable way of life. Being a part of a rural community also played an important role in creating the life these farmers sought.

\section{Profitability}

Top-performing farmers had a much keener focus on making good profits and they knew which aspects of their operations made the best returns, and consequently, this was where they focused efforts. Coupled with this they were more likely than mid-tier performers to have firm plans in place for growing their operations, and a stronger appetite for borrowing to both increase returns and the size of their farming business.

A key factor in driving profitability was thorough planning and efficiency. Top-performing farmers often described themselves as good planners and they had a fervent focus on looking at ways of making their operations more efficient. Part of this relied on adopting innovative practices and also looking for ways to more efficiently implement common farming practices for less cost than mid-performing farmers. They knew that good infrastructure was critical to efficiency and they worked to maintain a well set-up operation.

"With fodder beet now, people say you have to do things this way so I did everything the opposite way. I do it my way, the simple way and make it work and do it for half the costs" (Southland, topperformer, male)

Top-performing farmers were interested in new technologies but only insofar as they would make them more efficient and provide a return on investment. Efficiency seemed to be the dominant driver for new technology making its way on to top-performing farms. Without a clear sense that something such as Electronic Identification (EID) or drones would create time savings and improved accuracy that would enhance overall performance, the new technology would remain outside the farm gate.

\section{Industry confidence}

A key factor that drove top farmers willingness to invest and grow was their strong confidence in the long-term sustainability of the New Zealand sheep and beef industry. All top-performers strongly believed that sheep and beef farming was going to continue to be profitable and sustainable well into the future, while delivering an enviable way of life. Their boldness was driven by both confidence in market demand for their quality products (mainly sheep meat) and confidence in their own ability to achieve even greater productivity behind the farm gate.

"I'm very confident. I have proven that you can get the same returns as a dairy unit off the same area. I think new markets that are opening up in China, although China is fickle, look good and promising" (Wairarapa, top-performer, male)

This confidence drove a greater appetite for change and an almost constant exploration of new ideas. Underlying this was both a determination to do better and a belief that they could. Most top-performers were experimenting with a percentage of their farm system every season. Through this experimentation they were not necessarily taking substantial risks but rather making calculated decisions on opportunities where they were reasonably confident of significantly increasing returns. And more often than not they were right.

Mid-teir farmers had mixed levels of confidence in the future of the industry. They were most likely to believe that their ability to earn greater returns was largely governed by off-farm influences. This group were not necessarily risk averse, rather they were slower to act and less confident to try something that was different from what they had been comfortably doing for years.

\section{The challenge of a dynamic environment}

Sheep and beef farmers work in a challenging dynamic environment making it difficult to solve the performance puzzle and get it right year after year. Top-performing farmers get it right more often than not and they gain a lot of satisfaction from excelling in a business where many just break even. Succeeding despite the fluid and unpredictable nature of the farming environment is a factor that drives top farmers to perform. They had a deep understanding of the entire farm system so if they tweaked one part of their operation they were cognizant of the impact it could have elsewhere. Many of them are competitive, they are reluctant to accept failure and work hard to be the best they can. Part of this hard work is paying constant attention to detail and making sure they are actively observing what is happening on their farm. This close focus on their farm means they are ready to respond and make decisions at the right time. Getting this timing right seems to be a key difference between top and mid-tier farmers.

"So a lot of monitoring and reporting and recording is fine, but you still have to be alive to what is happening around you because it is such a dynamic business" (Southland, top-performer, male)

Top-performing farmers paid close attention to the basics such as growing grass, keeping their stock healthy and feeding them well. Focusing on the detail was critical to getting these activities right. 


\section{Passion for industry and people}

Top-performing farmers were strongly driven by a passion for the industry and desire to see improvements right across the sector. This led to many of them being actively involved in industry initiatives such as extension activities and competitions. They were much more likely to take responsibility for their industry and less likely to play the 'blame game' when it came to industry challenges.

They were also more inclined to want to mix with other people within the industry, seeing them as critical to helping drive performance on their own farm. They liked to surround themselves with talent and bounce ideas off them to help drive performance in their farm business. Many of them were also good communicators, which helped them to ask the right questions and get the best information. There was also a theme of topperformers often being part of a strong farm team.

"I think also being a good communicator is a big plus. I think you always get the best out of your technicians, your specialists, your scientists, and your farm discussion groups because you communicate really well, and you do get the best out of people. Being prepared to sit and talk has been a real positive" (West Otago, top-performer, female)

\section{Passion for performance}

Top-performing farmers had clear goals, often articulating these using figures and concrete examples of where they planned to be and when they would get there. Some younger farmers had quite ambitious plans and were moving quickly to drive profitability.

Linked to achieving and meeting well-defined goals, among top-performers there was a greater interest in and commitment to benchmarking and record keeping. Keeping records of overall performance helped topfarmers to monitor if they were on track to meet their goals and targets.
"I keep lots of records, but I do that to remind myself how we are doing and because I strive for improvement - you have a record there of where you are at and try and better it" (Mid Canterbury, top-performer, male)

Mid-tier farmers tended to have fewer clearly defined goals and they appeared to have less conviction and confidence that they would achieve them. They placed more emphasis on the influence that external factors (such as climate and prices) would have on their profitability.

\section{Conclusion}

This study suggests that farmers are motivated by a range of factors when it comes to driving their businesses forward. Making a profit is important as it allows farmers to continue on the land. However, if the industry is to credibly engage with farmers to try new practices and improve their on-farm practices, it is critical this engagement is couched in a much broader set of values. These values include the centrality of family, legacy and the 'way of life' that is unique to sheep and beef farming.

The key difference between top-performing farmers and lower-performing ones is their ability to execute. The challenge for industry to help lift the performance of all farmers is a greater focus on execution support behind the farm gate.

\section{ACKNOWLEDGEMENTS}

Thanks to Lisa McCauley (Researcher Otago) and Gavin White (UMR Researcher Wellington) for assisting with interviewing farmers and the analysis of the full report.

Thanks to the 58 New Zealand sheep and beef farmers who warmly welcomed us into their homes, made us coffees, teas, soup, full meals and even offered beds to the travelling rural researchers. They spoke openly and freely about their passion for the industry and impressed us deeply with their skill and articulation. 